\title{
LA-UA B1-78I
}

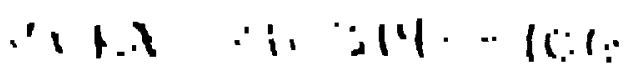

TITIE: A NOVEL CURRENT MONITOR FOR DC AND MODULATLD MAGNETS IN THE LOS ALAHIOS PROTON STORAGL RING

AUTHOR(S): Burton R. Sandberg

SUBMITTED TO: Particle Accelerator Conference Washington, DC March 11-13, 1981

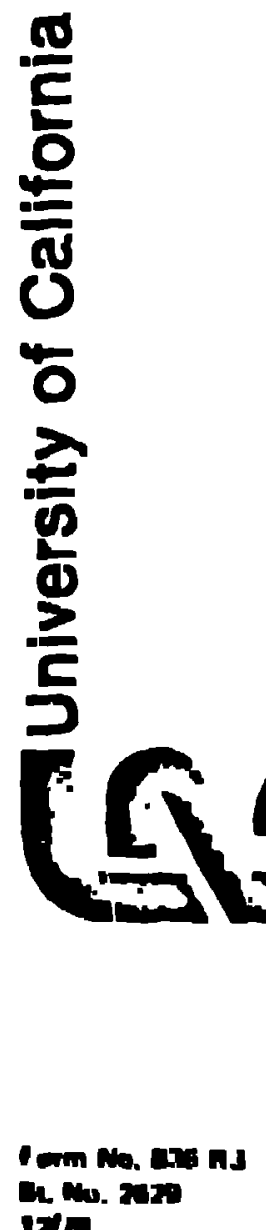

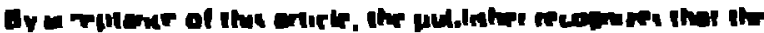

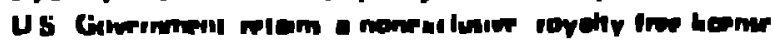

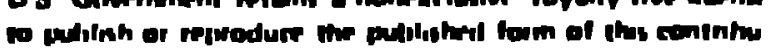

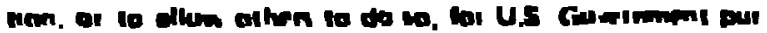
pons

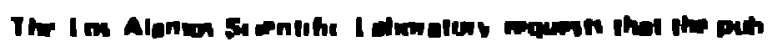

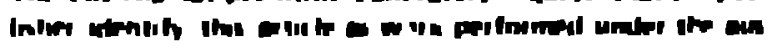

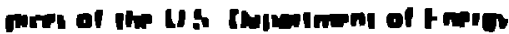


The zero flux dc current transformer has bren described tefire in literatura. ${ }^{1-2}$ This paicur endiavors tu present a mure allatytioal approasn. The: nit inod of demudulating the oc chillied is ncve:?, using a tilludonisin schenı rather thar, thu usual second-harminic method. The zurrent monitur miastires bipold currents up to $200 u$ A without physical contai $t$ of this singlietiarl primary. Choising the secolidary curririt as i $A$ sel: the turns ratic at i:?(vili). The mantiftit matierial

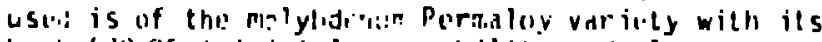

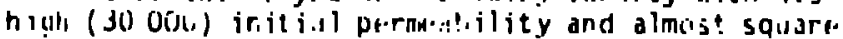
hysteresis locp. Its saturdion flux donsity is ationt

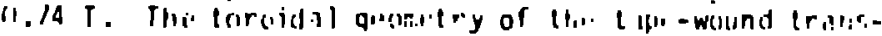

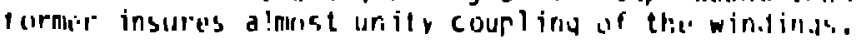

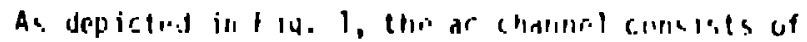

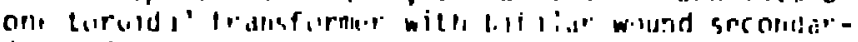

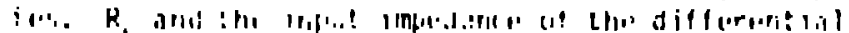

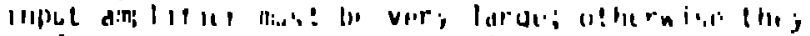

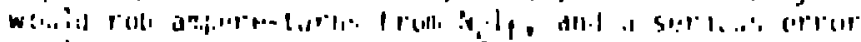

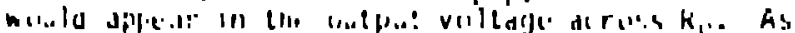

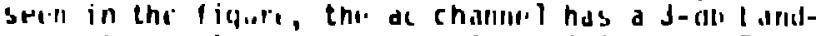

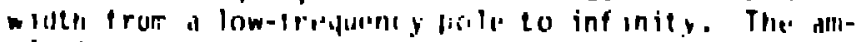

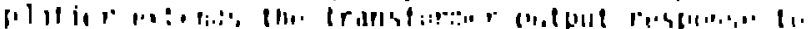

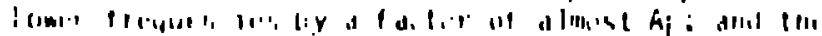

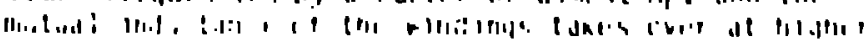

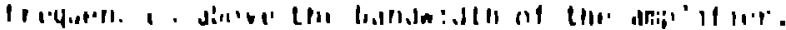

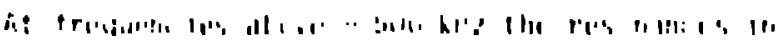

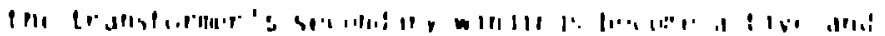

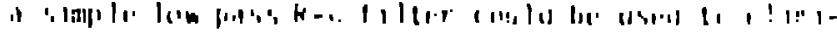

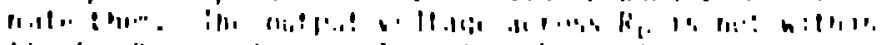

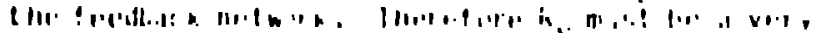

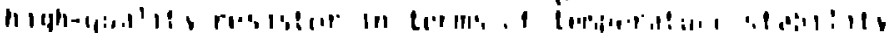

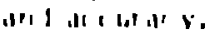

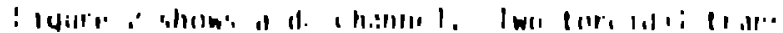

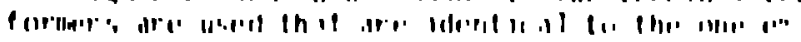

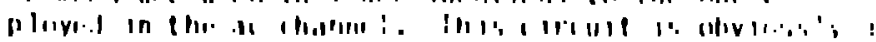

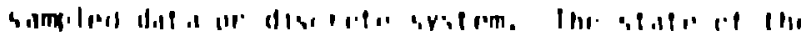

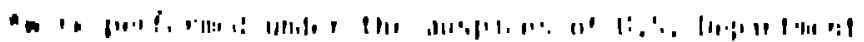
$11 \vdots 1,1,1$,

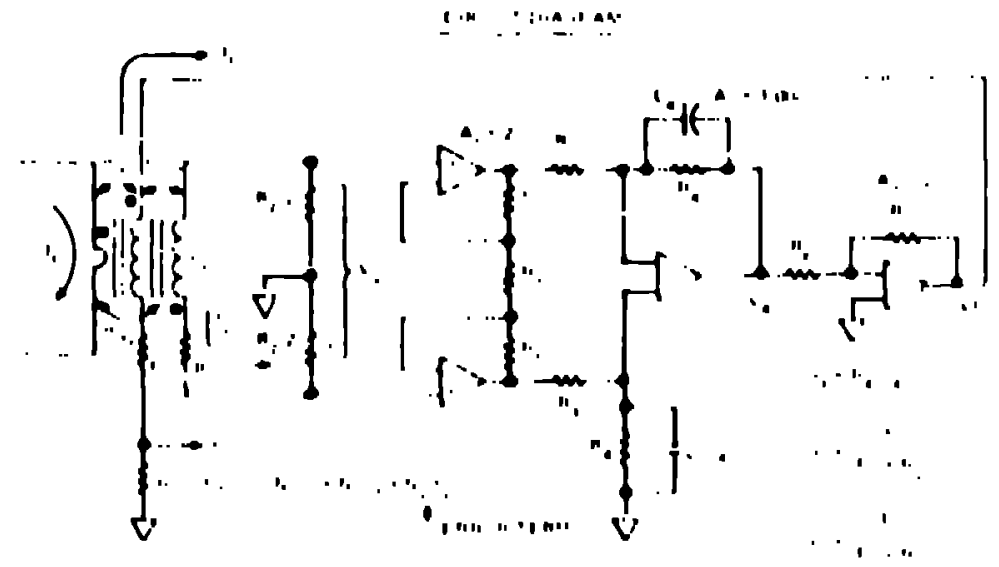

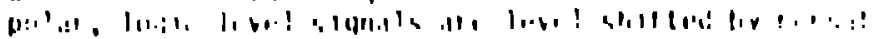

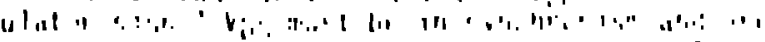

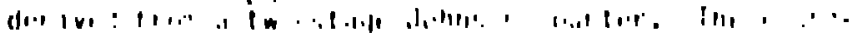

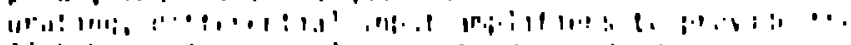

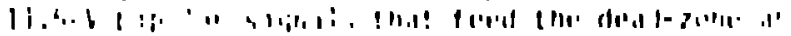

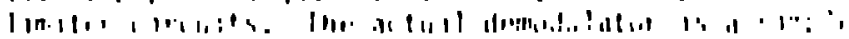
".." :

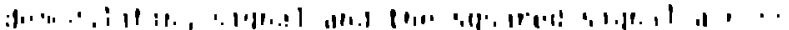

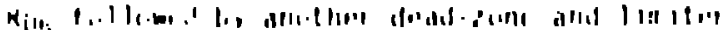

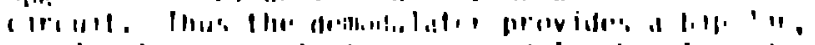

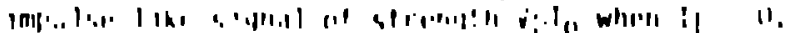

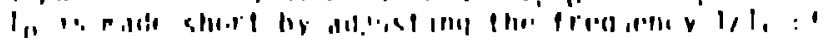

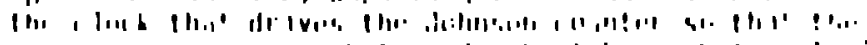

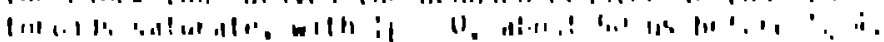

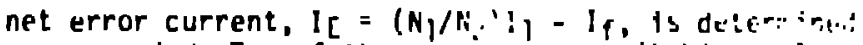
every period, $T_{S}$, of the squar wate stitching vultaid DR. If thic net eiror currelil il is nat zero, : if also flows through $R_{0}$ produs ing an outpis velidae.

The best way $t$ o understared $t h$ is de chanpe: is $:$ "

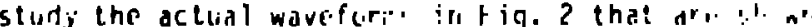

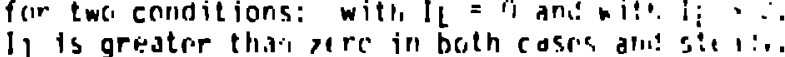

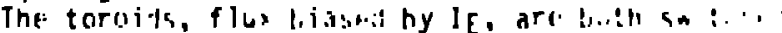

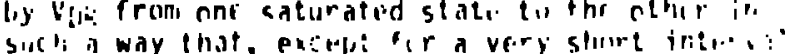

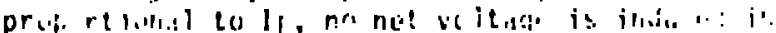

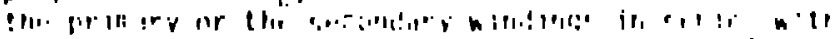

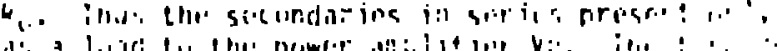

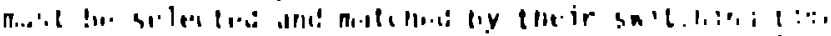

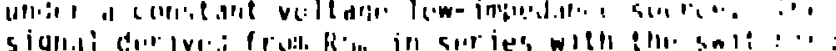

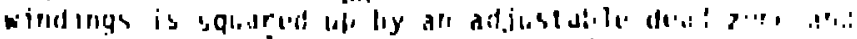

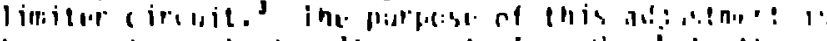

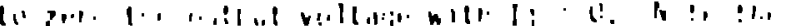

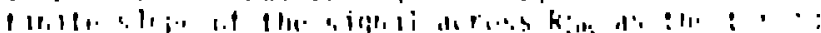

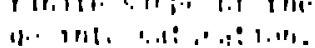

$$
\text { - }
$$

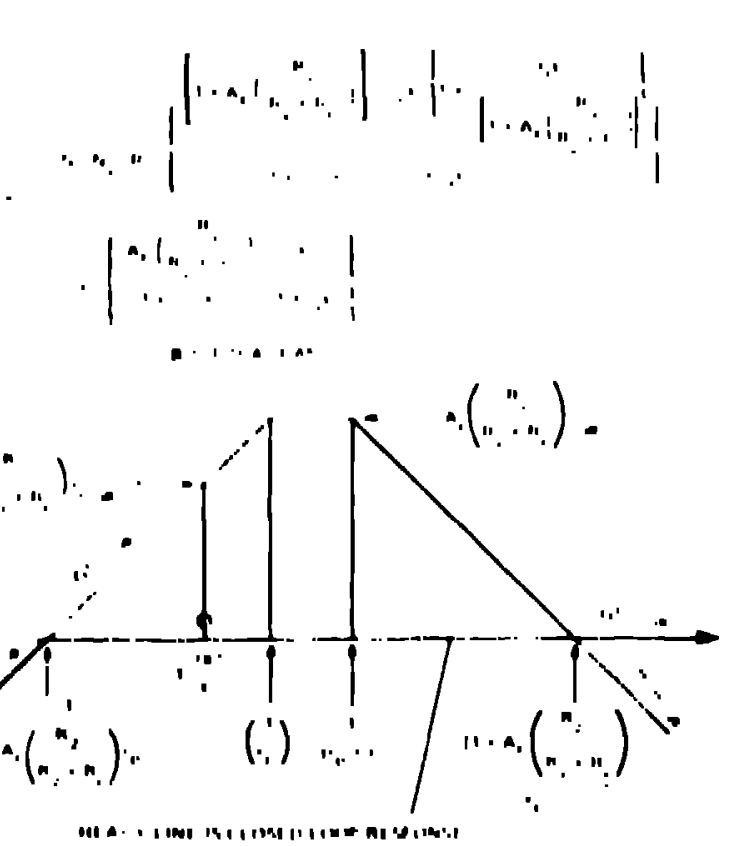

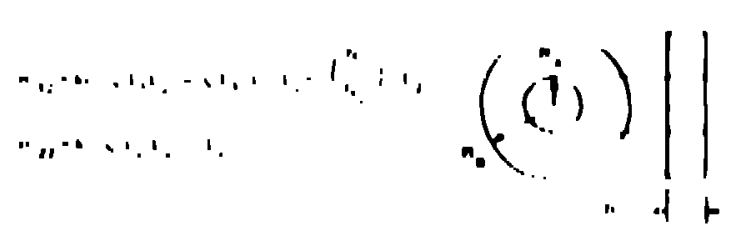
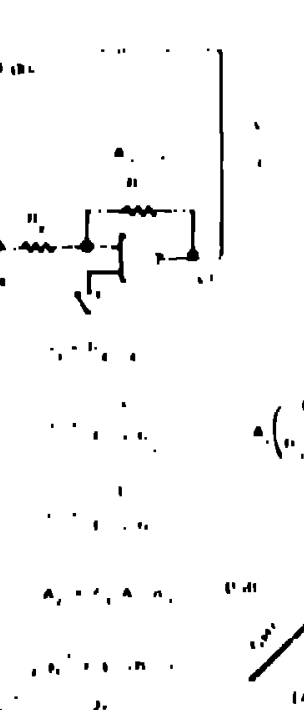

s.

I11. 1. 


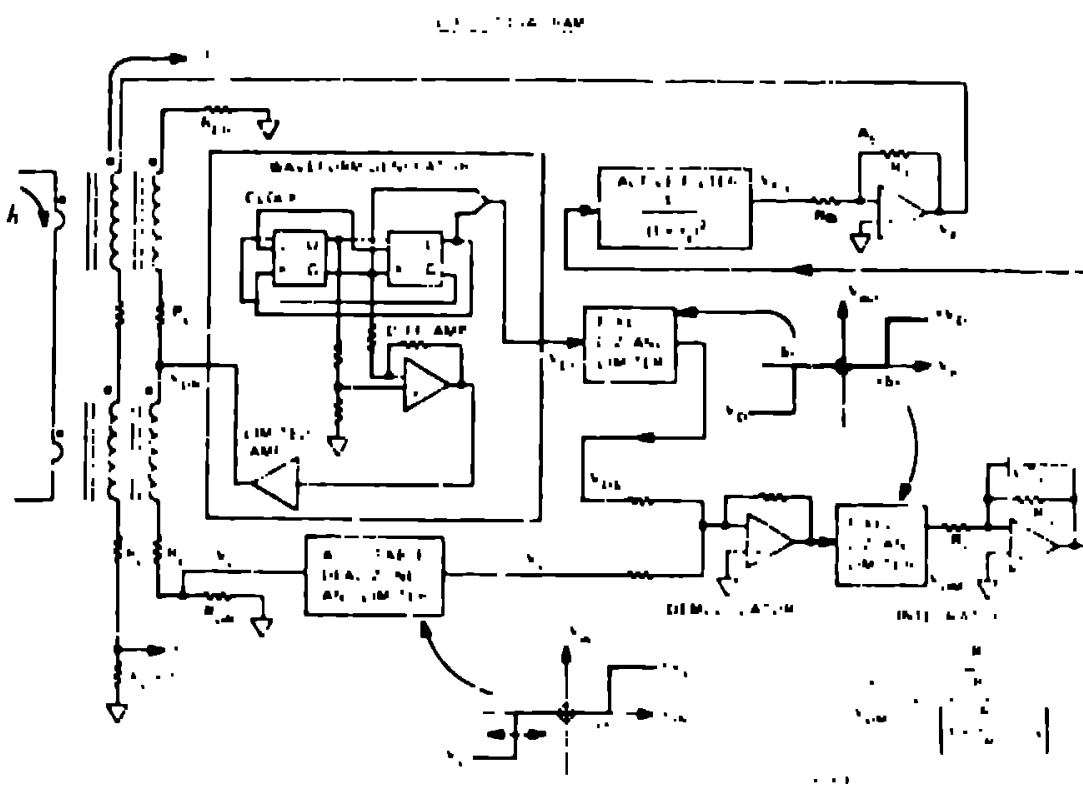

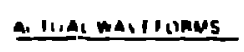

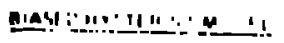
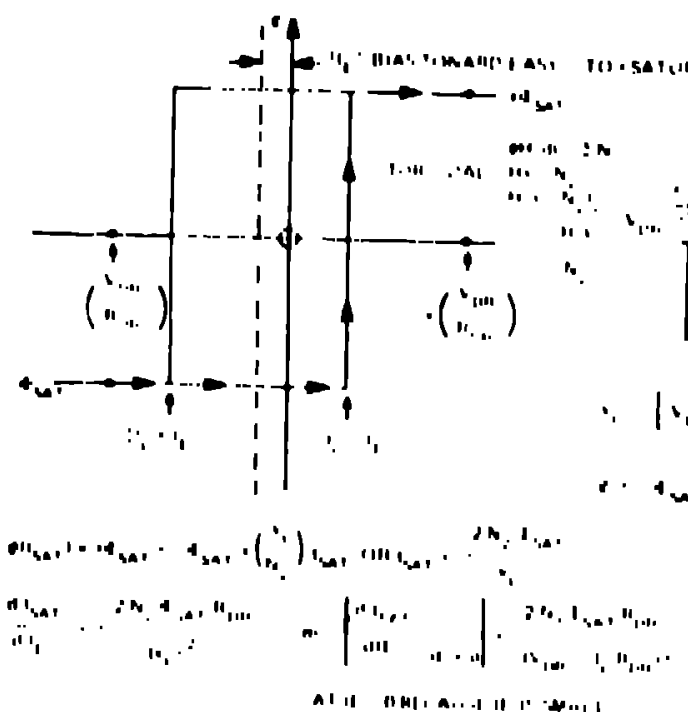

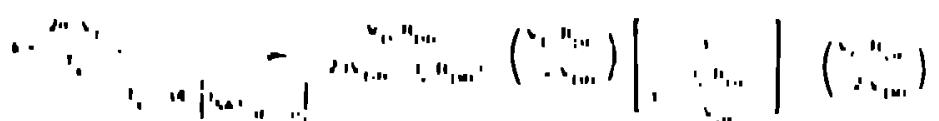

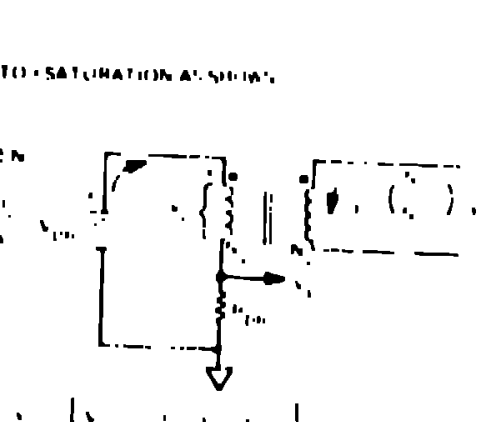

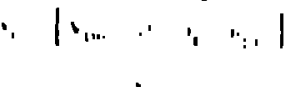

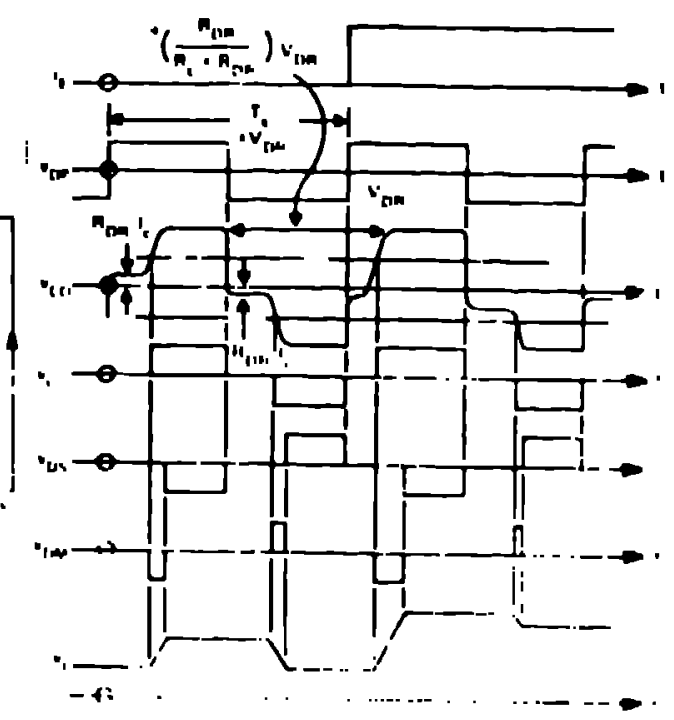

'.nu...:
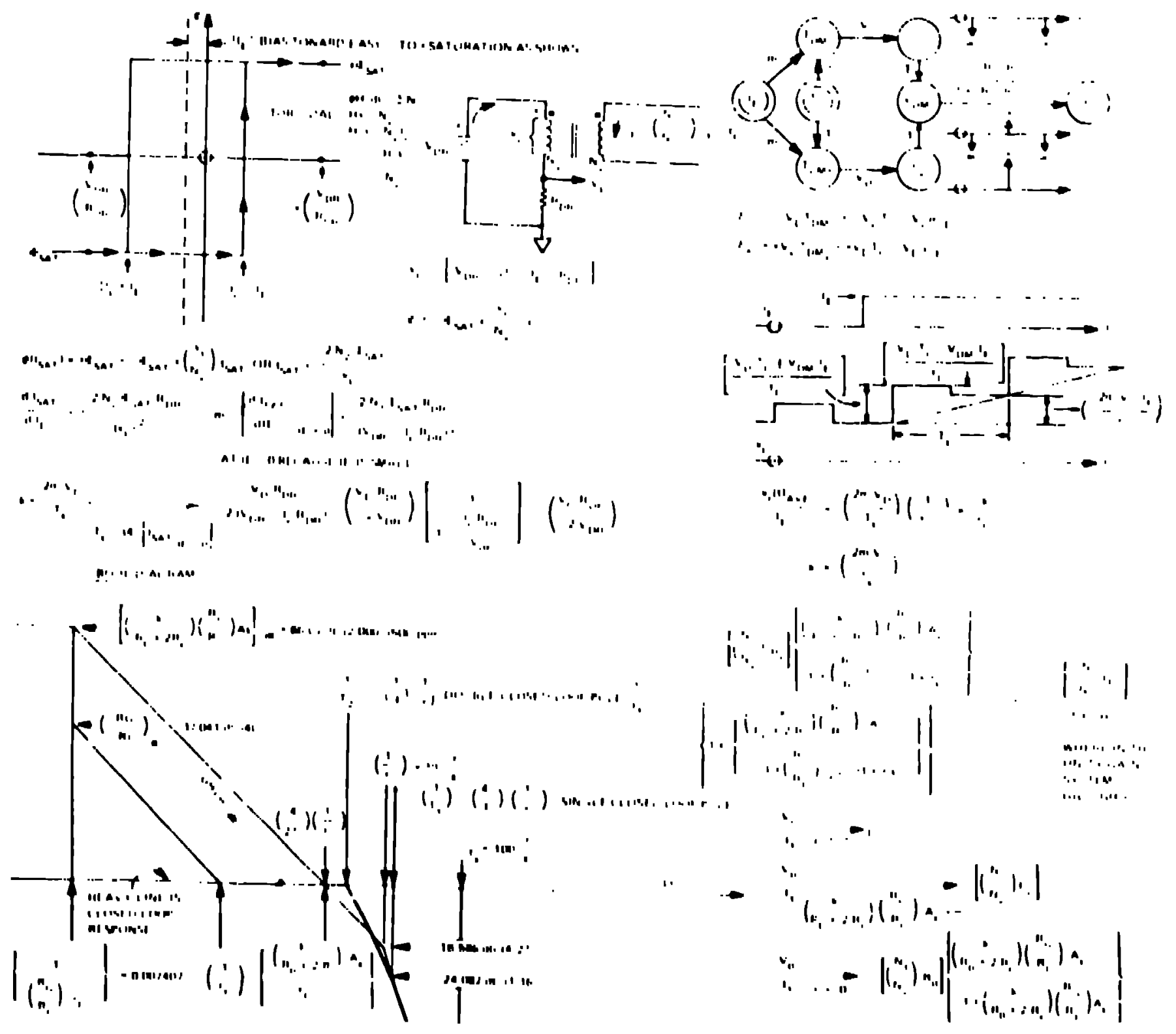

$$
\begin{aligned}
& \mid \begin{array}{l|l}
|c| & 1
\end{array}
\end{aligned}
$$

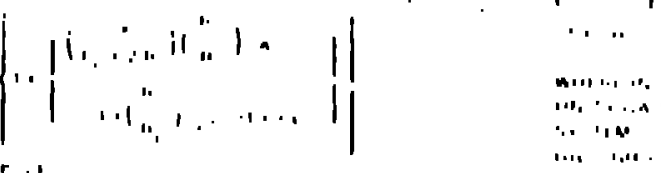

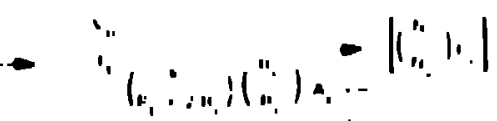

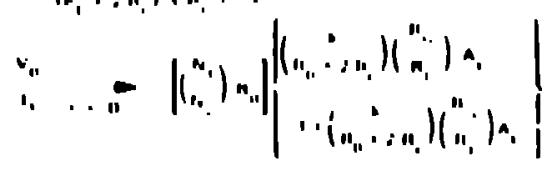

$111 . ;$
$;$ 


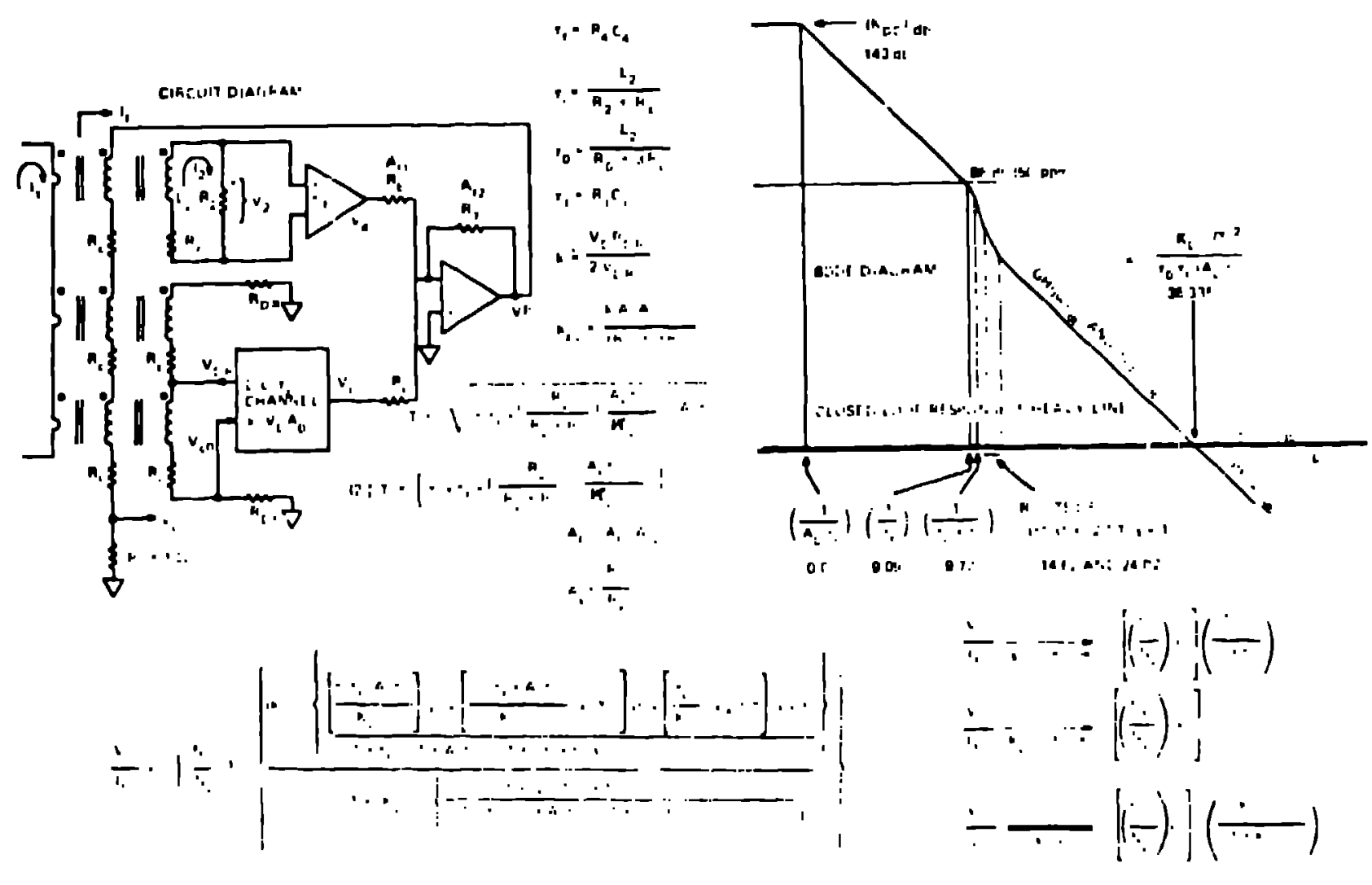

114. i.

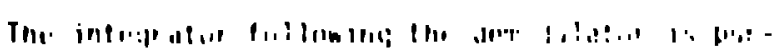

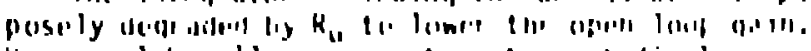

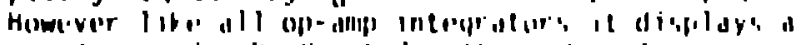

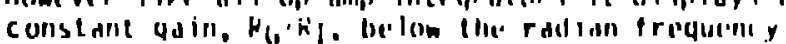

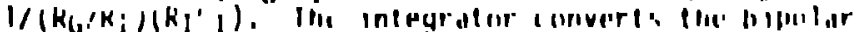

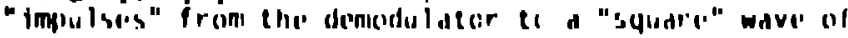

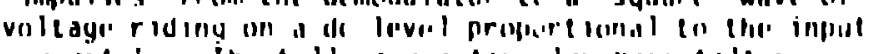

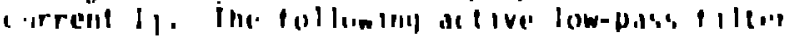

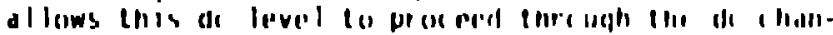

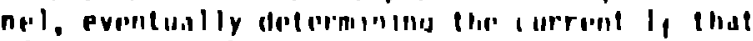
$f$ lows through $R_{0}$.

I igure a also shows a stinal flow graph of the

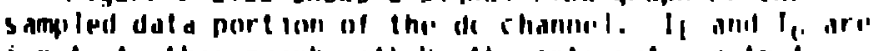

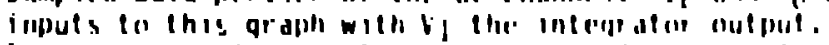

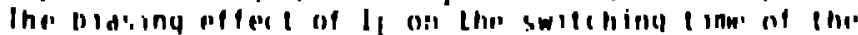

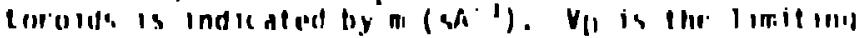

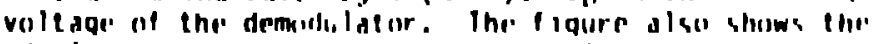

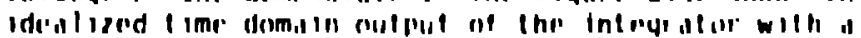

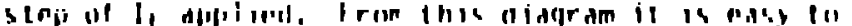

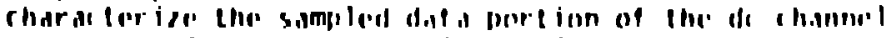

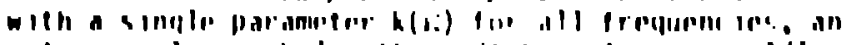

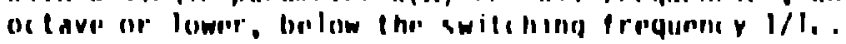

It remalns la relate m and t to other circull bla ramelers. Ior this a simplas I lua-biased hystrrees

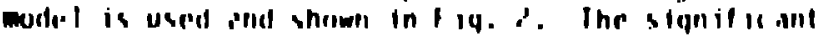
approximat fon hate is that ls is four I imes the

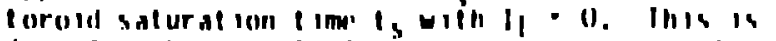

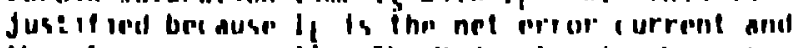
elerefore very smali. The Hode plat is shown in I 19. I. Using the irflerion of no ringing in th" output of this third-order system, Ine yain hil is adjusted so that fwe of the c lospel loup be ies merye an thi, neyal iver real axis.

Io have current manilur wilh sll plim resolut lon al de. and still have a wile banciwidth, thre at and do

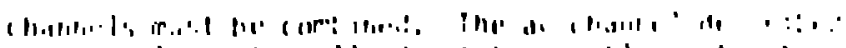

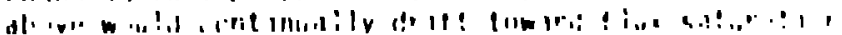

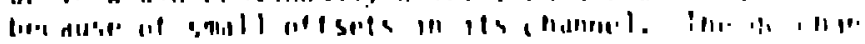

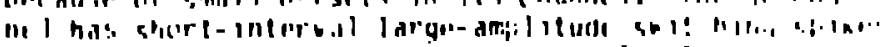

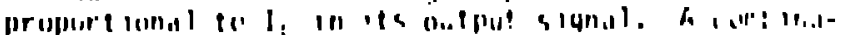

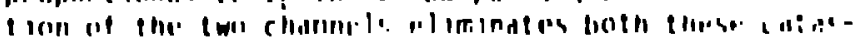

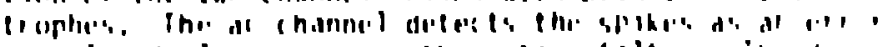

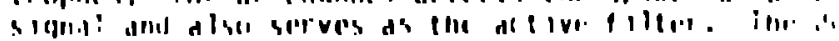

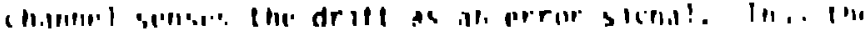

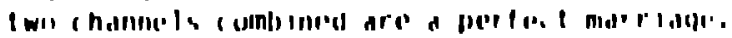

I legure \& shows a summing amplifier as the methide if rombinalion. Ihere are now three fordids. A stalliled,

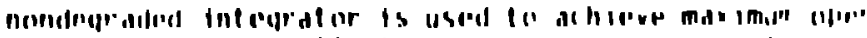

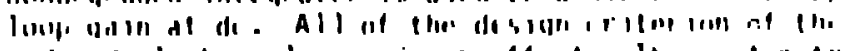

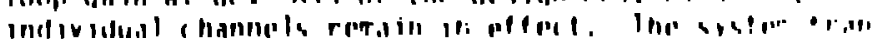

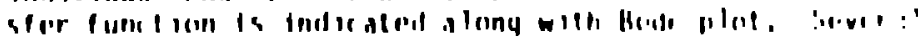

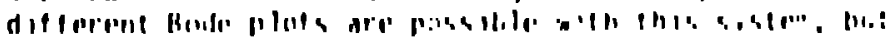

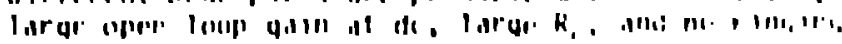

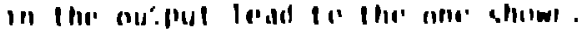

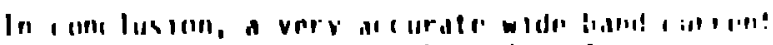

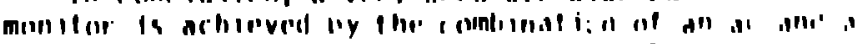

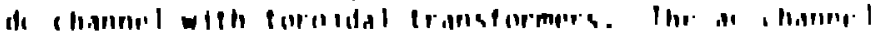

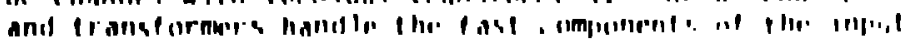

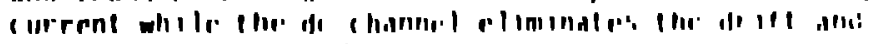

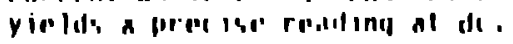

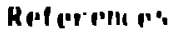

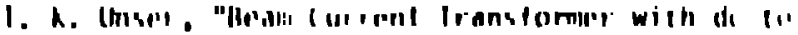

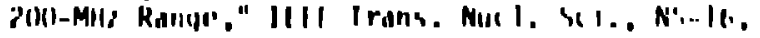
$414(1) \mathrm{III}$.

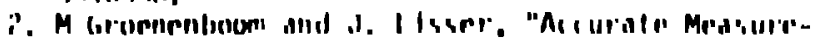

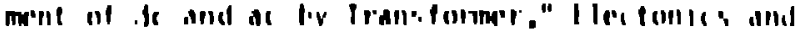

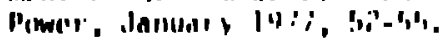

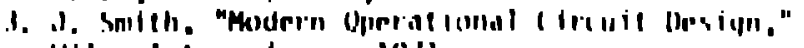
HIIry-Interse Irne $19 / 1$. 